Available online at www.jmle.org

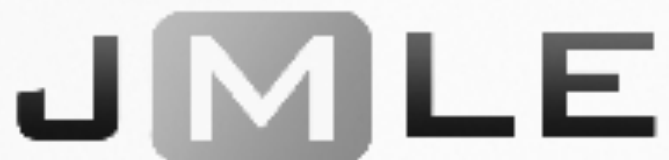

The National Association for Media Literacy Education's

Journal of Media Literacy Education 8(2), 1 - 21

\title{
Predicting Parental Mediation Behaviors: The Direct and Indirect Influence of Parents' Critical Thinking About Media and Attitudes about Parent-Child Interactions
}

\author{
Eric C. Rasmussen, Shawna R. White, Andy J. King, \\ Steven Holiday and Rebecca L. Densley \\ Texas Tech University
}

\begin{abstract}
Many parents fail to interact with their children regularly about media content and past research has identified few predictors of parents' engagement in parental mediation behaviors. This correlational study explored the relationship between parents' critical thinking about media and parents' provision of both active and restrictive mediation of television content. Results revealed that parents' critical thinking about media is positively associated with both active and restrictive mediation, relationships mediated by parents' attitudes toward parent-child interactions about media. These findings suggest that media literacy programs aimed at improving parents' critical thinking about media may be an effective way to alter children's responses to media exposure and that these media literacy programs should promote positive attitudes toward parental mediation.
\end{abstract}

Keywords: media literacy, parental mediation, media effects, children, media, television, attitudes, behaviors, intervention

Research shows that parent-child media-related interactions-often referred to as parental mediation behaviors - are an effective way to alter the influence of media exposure on children's well-being (Austin, Hust, \& Kistler, 2009; Chakroff \& Nathanson, 2008; Nathanson, 2001). Due to consistent empirical evidence showing parental mediation enhances positive effects and prevents negative effects of media exposure on children's well-being (Buijzen \& Valkenburg, 2005; Chakroff \& Nathanson, 2008), scholars, educators, and pediatricians have called on parents to involve themselves more actively in 
discussing and monitoring their children's media use (AAP, 2011; Brown, Shifrin, \& Hill, 2015). Despite recommendations, the majority of youth in the United States report they do not function under any rules or restrictions from their parents regarding the type or amount of television content they can watch (Rideout, Foehr, \& Roberts, 2010). Furthermore, parents report that they talk with their children about television even less than they set rules (Vittrup, 2009). In order to influence children's responses to media exposure positively, researchers should determine what can be done to identify factors that predict parents' motivations to be more involved with their children's media use.

Previous research found parents who engage in parental mediation tend to be motivated by negative attitudes about media content and by concern about potentially negative effects of media exposure (Bybee, Robinson, \& Turow, 1982; Mendoza, 2009). Some of the goals of adult media literacy programs (see Leivens, 2015) include increasing one's ability to think critically about media (Austin, Pinkleton, Radanielina-Hita, \& Ran, 2015) and empowering parents to make good choices about their children's media exposure through increased knowledge about the potential effects of media exposure (AAP, 2011). It is possible that parents with greater ability to think critically about media are more likely to engage in parental mediation. The present study investigated the relationship between parents' critical thinking about media, attitudes about parent-child interactions about media, and parental mediation behaviors.

\section{Media Literacy among Parents}

The present study conceptualizes media literacy as one's ability to decode, evaluate, and analyze media content in a variety of formats (Aufderheide, 1993; Center for Media Literacy, 2015). Most media literacy intervention research involves programs aimed at improving the media literacy skills of children, including the ability to analyze media content and sources critically (Austin et al., 2015). In order to teach media literacy skills to children, adults (i.e., parents and teachers) should have higher levels of media literacy, although this is not always the case (Potter, 2014). Teachers, those most often involved with implementing media literacy programs in schools, receive littleif any - media education and rarely discuss media literacy concepts in training or staff development (Kellner \& Share, 2005). Similarly, pediatricians receive little media literacy training, as less than one-third of accredited pediatrician residency programs teach their students about the influences of media exposure on the well-being of children and adolescents (Rich \& Bar-on, 2001). Pediatricians lacking training on media literacy seems understandable given the wealth of other information needed to be conveyed during residency, but that leaves only one other group of adults with the potential to regularly interact with children about media, and this is parents.

Parental media literacy levels may be even lower than those of teachers and pediatricians because parents rely on the expertise of child development and healthcare professionals to provide information for parenting decisions (Rich, 2014). In addition, parental mediation efforts are often not based on theory or research, but rather parents' personal experiences (Potter, 2010). Parents are 
relatively unaware of the effects that media messages can have on attitudes and behaviors, whereas such awareness is present among people with higher levels of media literacy (Potter, 2010). Parents also tend to believe their own children are at less risk of being affected by exposure to sexual and violent media content than other children (Meirick, Sims, Gilchrist, \& Croucher, 2009; Nathanson, Eveland, Park, \& Paul, 2002; Tsfati, Ribak, \& Cohen, 2005). A lack of awareness of potential media effects corresponds with parents' lack of concern about media content to which their children are exposed. For example, survey research found that most adults are not bothered "a lot" by violent and sexual media content in the U.S. (Pew, 2005) and the U.K. (Ofcom, 2014). Interviews with parents have found a similar lack of concern (Jordan, Hersey, McDivitt, \& Heitzler, 2006).

If parents have low levels of media literacy, then one may expect their children to have little access to developing their own media literacy skills, as parents are in the best position to influence their children's responses to media exposure (Browne, 1999; Hogan, 2001). Indeed, scholars have called for the provision of information about media content to parents in order to influence children's media exposure more positively (Bushman \& Cantor, 2003). When parents do make attempts to influence children's responses to media exposure, parental mediation takes place.

\section{Parental Mediation}

Parental mediation refers to parent-child interactions about media and generally encompasses three types of activities: active mediation, restrictive mediation, and coviewing. Active mediation refers to parent-child conversations about media and media content. Restrictive mediation refers to parent-enacted rules and restrictions related to children's media use. Coviewing refers to parents consuming media messages with their children (Nathanson, 2001; Valkenburg, Krcmar, Peeters, \& Marseille, 1999). Parents who engage in consistent parental mediation do so with the intent to impact how, and the extent to which, media exposure influences children (Rasmussen, 2013). Parents concerned with media content and its effects employ parental mediation behaviors to protect their children's well-being (Nathanson et al., 2002). Researchers regard parental mediation as the enactment of parental media literacy (Mendoza, 2009) or as the sharing of parental media literacy skills with children (Austin et al., 2015). There are, however, few studies examining the relationship between parental media literacy and parental mediation activities. As Mendoza (2009) notes, "media literacy and the field of parent media education lack conversation with the parental mediation literature" (p. 29).

Only a handful of studies explore aspects of the relationship between parental media literacy and parental mediation practices. For example, a survey of parents found that media literacy, represented largely by the parents' critical thinking toward media sources and content, was positively associated with parents' expectations that any future conversations they might have with their children about certain media messages would positively influence children's well-being (Austin et al., 2015). In addition, the ability of parents to assess food 
advertising critically associated positively with more parent-child discussions about advertising claims (Hindin, Contento, \& Gussow, 2004). The extant literature currently lacks research that examines the relationship between parents' ability to think critically about media and parental mediation of children's television exposure. Past research does suggest, however, that the relationship between parents' critical thinking about media, as one indicator of parental media literacy, and parental mediation is likely mediated by parents' attitudes toward these media-related interactions.

\section{Attitudes Toward Media-Related Interactions with Children}

Because of the strength of parents' influence on children (Pequegnat \& Szapocznik, 2000), many interventions designed to alter children's behaviors first attempt to change parenting behaviors, which, in turn, have been shown to alter children's attitudes and behaviors (Hutchinson \& Wood, 2007). These communication interventions aim to bolster protective parenting behaviors and skills by altering parents' knowledge about the risks their children face and by altering parents' attitudes about parent-child communication and other protective parenting behaviors (see, e.g., Maria, Markham, Bluethmann, \& Mullen, 2015). A review of these interventions found that programs often succeed at improving parents' attitudes toward sexual health communication and, ultimately, at increasing parent-child sexual health communication (Maria et al., 2015). Such increased engagement with these protective communication behaviors appears to result from the interventions' influence on parents' attitudes toward the protective behaviors. Similarly, we should expect parents who are more able to think critically about media to have more positive attitudes toward those behaviors that they know will decrease their children's susceptibility to negative effects of media exposure, such as parental mediation, than those who are less able to think critically about media. In this study, both active and restrictive mediation are considered protective parental mediation behaviors. Similar to past research, coviewing was excluded from this study because it is relatively ineffective at protecting children from undesirable media effects (see Valkenburg, Piotrowski, Hermanns, \& de Leeuw, 2013) and because coviewing is more common among parents who have a positive attitude about television (see, e.g., Austin \& Pinkleton, 2001; Dorr, Kovaric, \& Doubleday, 1989; Nathanson, 2001). Therefore, we predicted:

H1: Parents' critical thinking about media will be positively associated with their attitudes toward (a) active and (b) restrictive mediation.

\section{Attitude-Behavior Relationship}

Attitudes toward behaviors consistently predict behavioral intentions (for a review see Ajzen, 2012) and behaviors themselves (see, e.g., Kraus, 1995; McEachan, Conner, Taylor, \& Lawton, 2011). If attitudes about a behavior can be changed, then behaviors are likely also modifiable (Smith \& Mackie, 2007). For example, theories predicting behavior through a reasoned action approach (see Ajzen, 2012) suggest that attitudes are highly predictive of behaviors. 
Attitudes are often stronger predictors of behaviors than other constructs such as subjective norms (O'Keefe, 2002).

The consistent relationship between attitudes and behaviors has been demonstrated in a broad range of parenting research, beginning as early as when adults make a decision to become a parent. For example, adults' positive attitudes about childbearing correlate to rates of marital childbearing (Barber, 2001). Parents' attitudes toward using medicine to reduce a child's fever are also related to their intentions to use medication when a child has a fever (Walsh, Edwards, \& Fraser, 2009). Past research indicates that parents are more likely to intend to engage in parent-child communication if they have positive attitudes toward parent-child communication (Hutchinson \& Wood, 2007). And, although parents' attitudes about media content are highly predictive of parental mediation (Valkenburg et al., 1999; Warren, 2001), no research to date investigates the relationship between attitudes toward parental mediation and actual provision of parental mediation. Therefore, the present study tests the following predictions:

H2: Parents' positive attitudes toward active mediation will be positively associated with the frequency of their provision of active mediation.

H3: Parents' attitudes toward restrictive mediation will be positively associated with the frequency of their provision of restrictive mediation.

By combining the previous hypotheses, we are able to construct a proposed mediation model predicting that parents' critical thinking about media will be positively associated with the frequency of their provision of parental mediation through its relationship with parents' attitudes toward parental mediation. Specifically, we predicted:

H4: Parents' critical thinking about media will be positively associated with parents' positive attitudes toward active mediation, which will in turn be associated with the frequency of parents' provision of active mediation.

H5: Parents' critical thinking about media will be positively associated with parents' positive attitudes toward restrictive mediation, which will in turn be associated with the frequency of parents' provision of restrictive mediation.

\section{Participants}

\section{Method}

One hundred and seventy seven parents of children ages 4-11 $(M=7.28$, $S D=1.56$ ) in the United States recruited via Mechanical Turk (MTurk), an online task completion service, participated in the study. MTurk offers researchers a platform to collect information from an adult sample and has been used increasingly across the social sciences (Buhrmester, Kwang, \& Gosling, 2011; Casler, Bickel, \& Hackett, 2013), as well as specifically in communication 
research (see, e.g., Dixon, McKeever, Holton, Clarke, \& Eosco, 2015; LaMarre, 2013).

Participants were generally middle-aged $(M=33.82, S D=6.64)$ mothers $(55.9 \%)$ from a two-parent household $(79.1 \%)$ with at least an associate's degree (52.6\%), annual household income of less than $\$ 50,000(54.2 \%)$, and two or fewer children (74.6\%). Most participants were White/Caucasian (83.1\%), 8.5\% were Black/African American, $4.0 \%$ were Hispanic/Latino, $2.8 \%$ were Asian/Pacific Islander, and $1.1 \%$ were Native American/Alaska Native. Participants reported living in 154 unique U.S. zip code tabulation areas (ZCTAs).

Parents of school-age children were selected because their children are generally viewed as particularly vulnerable to the influence of media content due to their lack of real-world knowledge, their eagerness to learn, and their relative lack of experience with the media (Strasburger, Wilson, \& Jordan, 2014). In addition, parents of children in elementary school are more concerned about what their child sees on television and in movies than parents of both young children and of children ages 12-17 (Bleakley, Vaala, Jordan, \& Romer, 2014), making these parents more likely to engage in parental mediation activities with their children than they would be with preteens or teenagers (Austin, Knaus, \& Meneguelli, 1997; Chan \& McNeal, 2003; Valkenburg et al. 1999).

\section{Procedure}

The first author's university institutional review board approved all procedures. After agreeing to participate, participants completed an online survey containing 115 items measuring parents' critical thinking about media, attitudes toward parental mediation, frequency of provision of both active and restrictive mediation, attitudes toward violent and sexual television content, parent and child television exposure, demographics, and other attitudinal measures as part of a separate research project. Four items were attention items. An additional four participants completed the survey but were excluded - two because they incorrectly answered two or more attention items and two because Mahalanobis distance scores identified them as multivariate outliers.

\section{Measures}

Parents' critical thinking about media. As one indicator of parental media literacy, parents' critical thinking about media was measured via two three-item scales developed by Austin and colleagues (Austin et al., 2015). The first scale included items measuring critical thinking toward television content (e.g., "I think about things I see on TV before I accept them as believable"). The second scale included items measuring critical thinking toward sources (e.g., "I think about why someone created a message I see on TV"). Both measures employed a 7-point scale ranging from strongly disagree (1) to strongly agree (7). All six items were averaged to create an index, with higher scores indicating higher levels of critical thinking about media $(M=5.38, S D=1.06$, Cronbach's $\alpha=.87$ ). 
Attitudes toward parental mediation. Parents' attitudes toward active mediation was measured via an adaptation of similar measures used in past research (Byrne \& Lee, 2011) via 5 items on a 7-point scale ranging from strongly disagree (1) and strongly agree (7). Items asked about parents' agreement with five statements, such as "parents should sit down and talk with their kids about all of the bad and good things about media" and "parents should have regular conversations with their kids about media content the parent thinks is objectionable." Items were averaged to create an index, with higher scores indicating more positive attitudes toward active mediation $(M=5.79, S D=1.01$, Cronbach's $\alpha=.93$ ). Parents' attitudes toward restrictive mediation was similarly measured via 5 items, such as "parents should make rules about what kind of media content their kids can view" and "parents should not allow their kids to view certain media content until they are older." Items were averaged to create an index, with higher scores indicating more positive attitudes toward restrictive mediation $(M=5.88, S D=1.03$, Cronbach's $\alpha=.89)$. A principal components analysis with varimax rotation produced support for both factors. Eigenvalues greater than 1 constituted components. The first five items loaded onto one factor that explained $40.2 \%$ of the scale variance with coefficients ranging from .80 to .89 , and the second five items loaded onto a second factor that explained $35.4 \%$ of the scale variance with coefficients ranging from .74 to .86.

Parental mediation. Active mediation was measured via the 5-item active mediation subscale of the Television Mediation Scale (Valkenburg et al., 1999). Parents reported how often they have certain conversations with their child about television content on a 4-point scale ranging from never (1) to often (4), such as "how often do you try to help your child understand what s/he sees on TV and in the movies?" and "how often do you explain the motives of TV/movie characters?" Items were averaged to create an index, with higher scores indicating more frequent active mediation $(M=3.13, S D=.57$, Cronbach's $\alpha=$ $.85)$. Using the same 4-point scale, restrictive mediation was measured via the 5item restrictive mediation subscale from the Television Mediation Scale. Parents indicated how often they set rules or establish restrictions on their children's media use via items such as "how often do you set specific viewing hours for your child," and "how often do you forbid your child to watch certain programs." Items were averaged to create an index, with higher scores indicating more frequent restrictive mediation $(M=3.33, S D=.61$, Cronbach's $\alpha=.81)$.

Covariates. Covariates included child gender, child age, parent age, parent income, and parent education. For child gender, codes were assigned to male (1) and female (2). For parent income, parents selected which category best described their annual household income. Because the median national income is approximately $\$ 50,000$ (U.S. Census Bureau, 2015), parents fell into one of two groups: income of $\$ 50,000$ or less (0) and income greater than $\$ 50,000$ (1). For parent education, parents reported their highest level of education on a 7-point scale ranging from "some high school" to "graduate degree." Participants were categorized into two groups again: those who reported completing high school or with less formal education (0) and those with some college or more (1). In addition, covariates included parents' attitudes toward violent and sexual 
television/movie content, and both parents' and children's television/movie exposure (described below). These were included in analyses because, respectively, attitudes toward television content are related to the frequency of parental mediation (e.g. Nathanson, 2001) and because frequency of exposure to media content may alter beliefs about the desirability of the content (Fisher et al., 2009). A correlation matrix of all study variables can be found in Table 1.

Parents' attitudes toward violent and sexual television content. Parents' attitudes toward violent television content was measured via the product of two items, similar to past research (Bybee et al., 1982). Parents responded to one item asking them to indicate what they think the role of television and movies play in increasing children's aggressive behavior on a 4-point scale ranging from not at all an important contributory cause (1) to they are the cause (4). The second item asked parents to report how concerned they are about violent content in television and movies on a 4-point scale ranging from not at all concerned (1) to very concerned (4). Higher scores of the product of the two items indicate more negative attitudes toward violent television/movie content $(\mathrm{M}=6.70, \mathrm{SD}=3.62$, $r=.30)$. Attitudes toward sexual content were measured similarly $(\mathrm{M}=6.98, \mathrm{SD}$ $=3.71, r=.47$ ).

Television/movies exposure. Parents reported both their own and their child's average time spent watching television and movies on weekdays and on weekends via two items each with 13 response options ranging from less than 1 hour (1) to more than 6 hours (13). Weekday average scores were multiplied by five, weekend scores were multiplied by 2 , and the product of weekday and weekend scores was divided by 7 in order to obtain an average daily exposure score, with higher scores indicating more exposure (parent $M=6.68, S D=3.29$; child $M=4.91, S D=2.68$ ).

\section{Results}

Hypothesis 1 predicted that parents' critical thinking about media would be positively associated with their attitudes about active and restrictive mediation. Hierarchical linear regression with child age, child gender, parent age, parent gender, parent education, and income entered in the first block; parents' attitudes about violent and sexual television/movie content entered in the second block; parents' and children's television/movie exposure entered in the third block; and parents' critical thinking about media entered in the fourth block indicated that parents' critical thinking about media accounted for $4.6 \%$ of the variance in attitudes toward active mediation (See Table 2). Specifically, parents with higher levels of critical thinking about media were more likely to have positive attitudes about active mediation $(\beta=.213, p<.001)$. The same analysis with attitudes toward restrictive mediation as the dependent variable revealed that parents' critical thinking about media accounted for $2.4 \%$ of the variance in attitudes toward restrictive mediation (see Table 2). Specifically, parents with higher levels of critical thinking about media were more likely to have positive attitudes about restrictive mediation $(\beta=.158, p=.02)$. Therefore, results support $\mathrm{H} 1$. 
Hypothesis 2 predicted that parents' positive attitudes toward active mediation would be positively associated with their provision of active mediation. Hierarchical linear regression with child age, child gender, parent age, parent gender, parent education, and income entered in the first block; parents' attitudes about violent and sexual television/movie content entered in the second block; parents' and children's television/movie exposure entered in the third block; and parents' attitudes toward active mediation entered in the fourth block revealed that attitudes toward active mediation accounted for $5.9 \%$ of the variance in active mediation (see Table 3). Specifically, parents with more positive attitudes toward active mediation reported more frequent provision of active mediation $(\beta=.167, p=.001)$. Therefore, results also supported $\mathrm{H} 2$.

Hypothesis 3 predicted that parents' positive attitudes toward restrictive mediation would be positively associated with their provision of restrictive mediation. Hierarchical linear regression with the same variables as the previous analysis entered in the first three blocks, and with parents' attitudes toward restrictive mediation in the fourth block revealed that attitudes toward restrictive mediation accounted for $15.5 \%$ of the variance in restrictive mediation (see Table 3). Specifically, parents with more positive attitudes toward restrictive mediation reported more frequent provision of restrictive mediation $(\beta=.280, p$ $<.001$ ). Therefore, regression analyses supported H3.

Hypothesis 4 predicted that parents' positive attitudes toward active mediation would mediate the relationship between parents' critical thinking about media and active mediation. The simple mediation model (see Figure 1) between critical thinking about media and active mediation through attitudes toward active mediation was estimated using OLS regression, with covariates of: child age, child gender, parent age, parent gender, parent education, income, parent and child television/movie exposure, and attitudes toward violent and sexual TV content. Specifically, we employed Hayes' (2013) PROCESS SPSS macro (model 4), which estimates both direct and indirect effects of simple mediation models. The total effect $(c)$ of parents' critical thinking about media on active mediation was significant $(b=.099, t=2.45, p=.01,95 \%$ CI [.0194, $.1788])$. The direct effect $\left(c^{\prime}\right)$, removing the effect of the mediator, was not significant $(b=.068, t=1.67, p=.10,95 \%$ CI $[-.0127, .1490])$. The indirect effect through attitudes toward active mediation, however, was significant $(b=$ $.031,95 \%$ CI $[.0078, .0681])$. Therefore, the mediation analysis supported H4. 
E. Rasmussen et al / Journal of Media Literacy Education (2016) 8(2), 1 - 21
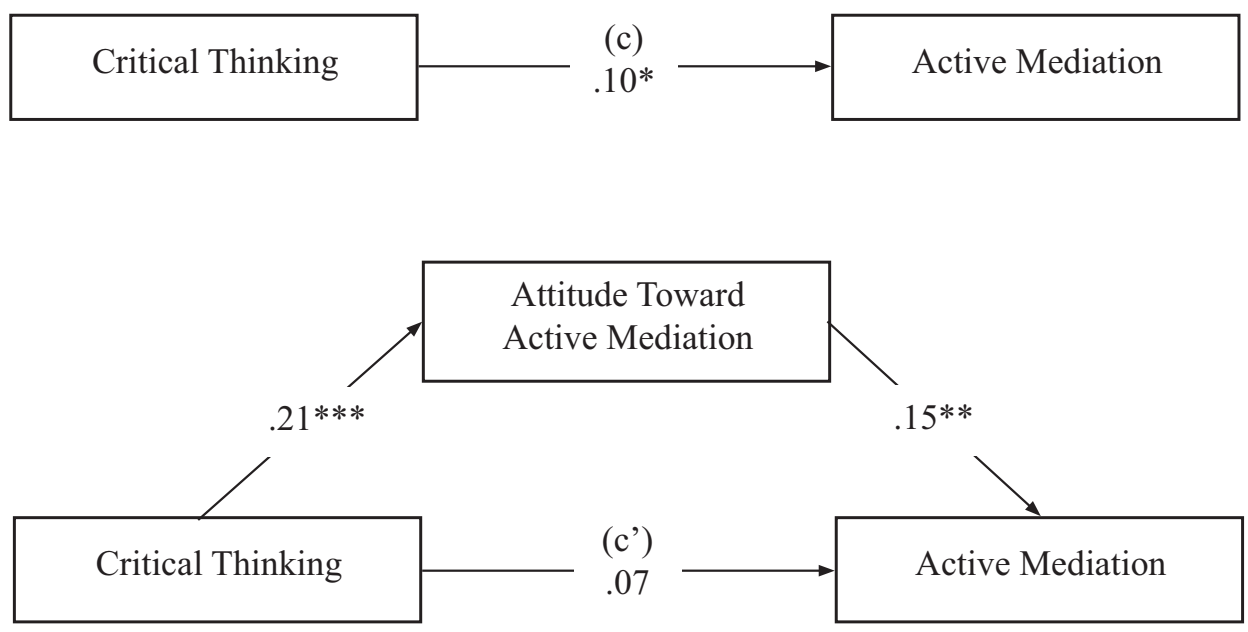

Figure 1.

Proposed model of the indirect relationship between parents' critical thinking about media and frequency of their provision of active mediation.

${ }^{*} p \leq .05 .{ }^{* *} p \leq .01 .{ }^{* * *} p \leq .001$. 
Table 1. Correlation Matrix of Study Variables

\begin{tabular}{|c|c|c|c|c|c|c|c|c|c|c|c|c|c|c|c|}
\hline & 1 & 2 & 3 & 4 & 5 & 6 & 7 & 8 & 9 & 10 & 11 & 12 & 13 & 14 & 15 \\
\hline (1) Child Age & - & & & & & & & & & & & & & & \\
\hline (2) Child Gender & .07 & - & & & & & & & & & & & & & \\
\hline (3) Parent Age & $.34 * * *$ & .05 & - & & & & & & & & & & & & \\
\hline (4) Parent Gender & -.07 & .15 & -.02 & - & & & & & & & & & & & \\
\hline (5) Parent Education & -.06 & -.10 & .03 & -.05 & - & & & & & & & & & & \\
\hline (6) Income & .06 & .04 & $.16^{*}$ & -.06 & $.16^{*}$ & - & & & & & & & & & \\
\hline $\begin{array}{l}\text { (7) Violent Content } \\
\text { Attitude }\end{array}$ & -.01 & .00 & .11 & $.28 * * *$ & -.15 & -.11 & - & & & & & & & & \\
\hline $\begin{array}{l}\text { (8) Sexual Content } \\
\text { Attitude }\end{array}$ & .11 & .05 & .10 & $.19 *$ & -.13 & -.09 & $.69 * * *$ & - & & & & & & & \\
\hline $\begin{array}{l}\text { (9) Child TV/movie } \\
\text { Exposure }\end{array}$ & $.19 *$ & .07 & .01 & .11 & -.14 & -.11 & $.16^{*}$ & $.16^{*}$ & - & & & & & & \\
\hline $\begin{array}{l}\text { (10) Parent TV/movie } \\
\text { Exposure }\end{array}$ & .09 & -.04 & .04 & .10 & $-.17 *$ & $-.16^{*}$ & $.15 *$ & $.23 * *$ & $.56 * * *$ & - & & & & & \\
\hline $\begin{array}{l}\text { (11) Active Mediation } \\
\text { Attitudes }\end{array}$ & -.00 & .02 & $.15^{*}$ & $.42 * * *$ & -.09 & -.10 & $43 * * *$ & $.41 * * *$ & .09 & .13 & - & & & & \\
\hline $\begin{array}{l}(12) \text { Restrictive } \\
\text { Mediation } \\
\text { Attitudes }\end{array}$ & -.10 & .03 & .14 & $.32 * * *$ & -.04 & -.10 & $.44 * * *$ & $.43 * * *$ & .04 & .09 & $.63 * * *$ & - & & & \\
\hline (13) Critical Thinking & .07 & .05 & .12 & .13 & .12 & .08 & $.16^{*}$ & $.16^{*}$ & -.03 & -.06 & $.32 * * *$ & $.25 * *$ & - & & \\
\hline (14) Active Mediation & .02 & -.05 & .01 & $.27 * * *$ & -.07 & -.03 & .06 & .10 & .07 & .04 & $.33 * * *$ & $.17 *$ & $.22 * *$ & - & \\
\hline $\begin{array}{l}\text { (15) Restrictive } \\
\text { Mediation }\end{array}$ & $-.19 *$ & -.04 & .02 & $.29 * * *$ & -.09 & .00 & $.36 * * *$ & $.29 * * *$ & -.00 & .00 & $.43 * * *$ & $.56 * * *$ & $.21 * *$ & $\begin{array}{c}30 * * \\
*\end{array}$ & - \\
\hline
\end{tabular}

Note. ${ }^{*} p \leq .05, * * p \leq .01, * * * p \leq .001$. Correlations are two-tailed Pearson's r coefficients. 
Table 2. Hierarchical Linear Regression Analysis of the Relationship Between Parents' Critical Thinking About Media and Attitudes Toward Active (AM) and Restrictive (RM) Mediation

\begin{tabular}{|c|c|c|c|c|c|c|c|c|}
\hline & \multicolumn{4}{|c|}{ AM attitude } & \multicolumn{4}{|c|}{ RM attitude } \\
\hline & $\beta$ & $S E$ & $\mathrm{R}^{2}$ & $\Delta \mathrm{R}^{2}$ & $\beta$ & $S E$ & $\mathrm{R}^{2}$ & $\Delta \mathrm{R}^{2}$ \\
\hline Block One & & & .22 & $.22^{* * *}$ & & & .15 & $.15^{* * *}$ \\
\hline Child Age & -.02 & .05 & & & -.09 & .05 & & \\
\hline Child Gender & -.10 & .14 & & & -.03 & .15 & & \\
\hline Parent Age & $.03^{*}$ & .01 & & & $.03^{* *}$ & .01 & & \\
\hline Parent Gender & $.84^{* * *}$ & .14 & & & $.64^{* * *}$ & .15 & & \\
\hline Parent Education & -.24 & .22 & & & -.08 & .24 & & \\
\hline Income & -.19 & .14 & & & -.22 & .15 & & \\
\hline Block Two & & & .33 & $.11^{* * *}$ & & & .31 & $.15^{* * *}$ \\
\hline Violent Content Attitude & .04 & .03 & & & .05 & .03 & & \\
\hline Sexual Content Attitude & $.06^{*}$ & .02 & & & $.08^{* *}$ & .03 & & \\
\hline Block Three & & & .33 & .00 & & & .31 & .00 \\
\hline Child TV/movie Exposure & -.00 & .03 & & & -.01 & .03 & & \\
\hline Parent TV/movie Exposure & .00 & .03 & & & -.00 & .03 & & \\
\hline Block Four & & & .37 & $.05^{* * *}$ & & & .33 & $.02^{*}$ \\
\hline Critical Thinking & $.21^{* * *}$ & .06 & & & $.16^{*}$ & .07 & & \\
\hline
\end{tabular}

Note. All entries are unstandardized regression coefficients upon entry into the equation.

${ }^{*} p \leq .05 .{ }^{* *} p \leq .01 .{ }^{* * *} p \leq .001$. The sample size meets the minimum sufficient sample size criteria for regression analyses $(\mathrm{N} \geq 104+\mathrm{m})$ as outlined by Green (1991). 
Table 3. Hierarchical Linear Regression Analysis of the Relationship Between Attitudes Toward Active (AM) and Restrictive (RM) Mediation and Frequency of Provision of AM and RM

\begin{tabular}{|c|c|c|c|c|c|c|c|c|}
\hline & \multicolumn{4}{|c|}{ Active Mediation } & \multicolumn{4}{|c|}{ Restrictive Mediation } \\
\hline & $\beta$ & $S E$ & $R^{2}$ & $\Delta R^{2}$ & $\beta$ & $S E$ & $R^{2}$ & $\Delta R^{2}$ \\
\hline Block One & & & .09 & $.09^{*}$ & & & .14 & $.14^{* * *}$ \\
\hline Child Age & .02 & .03 & & & $-.08^{* *}$ & .03 & & \\
\hline Child Gender & -.12 & .09 & & & -.10 & .09 & & \\
\hline Parent Age & .00 & .01 & & & .01 & .01 & & \\
\hline Parent Gender & $.32^{* * *}$ & .08 & & & $.36^{* * *}$ & .09 & & \\
\hline Parent Education & -.12 & .14 & & & -.20 & .14 & & \\
\hline Income & -.00 & .09 & & & .04 & .09 & & \\
\hline Block Two & & & .10 & .01 & & & .22 & $.08^{* * *}$ \\
\hline Violent Content Attitude & .02 & .02 & & & $.03^{*}$ & .02 & & \\
\hline Sexual Content Attitude & .02 & .02 & & & .02 & .02 & & \\
\hline Block Three & & & .10 & .00 & & & .23 & .01 \\
\hline Child TV/movie Exposure & .01 & .02 & & & .00 & .02 & & \\
\hline Parent TV/movie Exposure & -.01 & .02 & & & -.01 & .02 & & \\
\hline Block Four & & & .16 & $.06^{* * *}$ & & & .38 & $.16^{* * *}$ \\
\hline AM Attitude (H2) & $.17^{* * *}$ & .05 & & & & & & \\
\hline RM Attitude (H3) & & & & & $.28^{* * *}$ & .04 & & \\
\hline
\end{tabular}

Note. All entries are unstandardized regression coefficients upon entry into the equation.

${ }^{*} p \leq .05 .{ }^{* *} p \leq .01{ }^{* * *} p \leq .001$ 
Hypothesis 5 predicted that parents' positive attitudes toward restrictive mediation would mediate the relationship between parents' critical thinking about media and restrictive mediation. The simple mediation model (see Figure 2) between critical thinking about media and restrictive mediation through attitudes toward restrictive mediation was estimated using OLS regression, with covariates of: child age, child gender, parent age, parent gender, parent education, income, parent and child television/movie exposure, and attitudes toward violent and sexual TV content. Again using Hayes' (2013) PROCESS SPSS macro (model 4), results revealed that the total effect $(c)$ of parents' critical thinking about media on restrictive mediation was not significant $(b=.077, t=1.89, p=.06,95 \%$ CI [$.0033, .1581])$. The direct effect $\left(c^{\prime}\right)$, removing the effect of the mediator, also was not significant $(b=.035, t=.92, p=.36,95 \%$ CI $[-.0397, .1088])$. The indirect effect through attitudes toward restrictive mediation, however, was significant $(b=.043,95 \%$ CI $[.0084, .0818])$. Therefore, the mediation analysis supported H5.

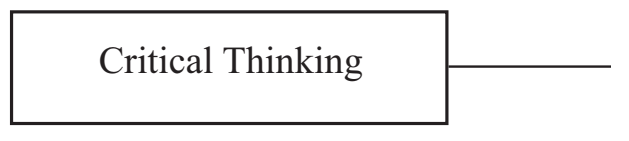

$(\mathrm{c})$
.08
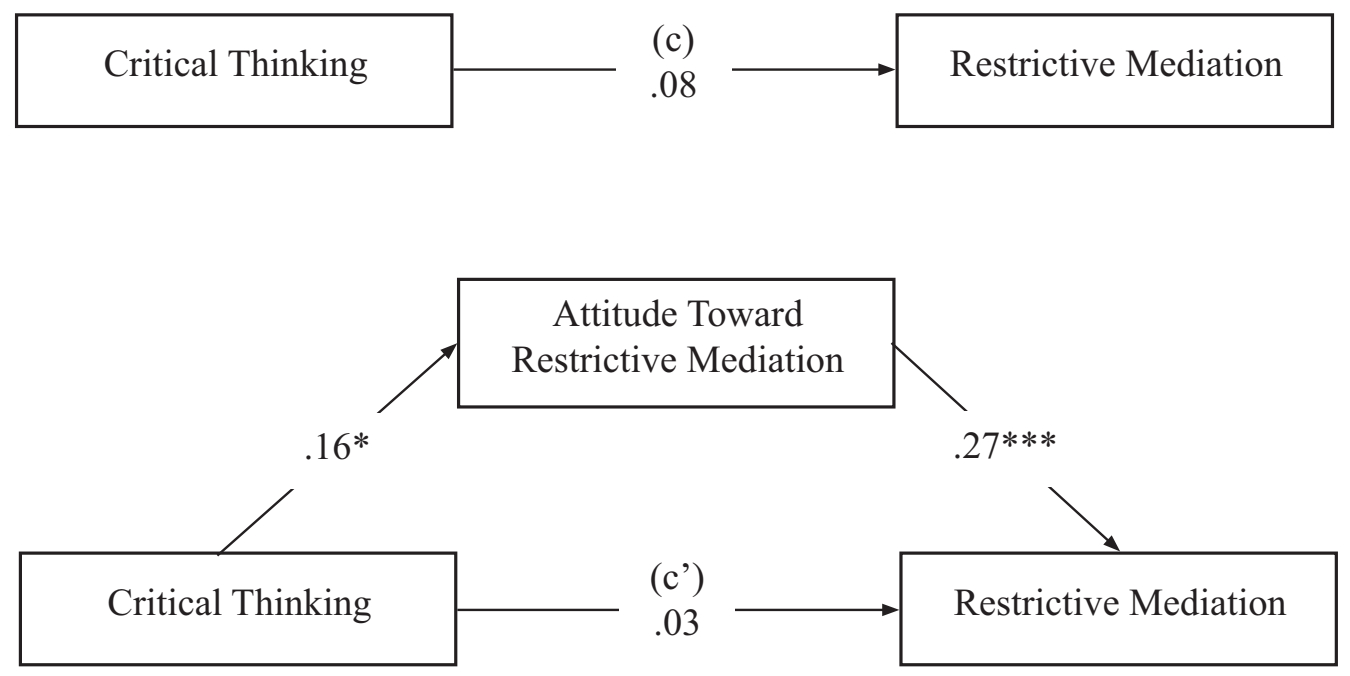

Figure 2. Proposed model of the indirect relationship between parents' critical thinking about media and frequency of their provision of restrictive mediation.

${ }^{*} p \leq .05 .{ }^{* *} p \leq .01{ }^{* * *} p \leq .001$.

\section{Discussion}

Research consistently shows that parental mediation is effective at altering children's responses to media exposure (Chakroff \& Nathanson, 2008) and experts encourage parents to increase the amount of parental mediation they provide (AAP, 2011). Empirical research suggests, however, that many children do not receive frequent parental mediation (Rideout et al., 2010; Vittrup, 2009). Results from the current study indicate parents with greater ability to think critically about media may be more likely to engage in parental mediation 
behaviors. Additionally, the present study found that parents' attitudes toward active and restrictive mediation mediate the relationship between parents' critical thinking about media and their mediation behaviors. Despite the effectiveness of parental mediation, some suggest that relying on parents to guide children's media experiences is not an effective strategy due to the paucity of parents' technical expertise, time, and communication skills (Livingstone, Van Couvering, \& Thumim, 2005).

This study provides initial evidence that parental media literacy, conceptualized in the present study as critical thinking about media sources and content, is a factor that predicts whether or not parents engage in active and restrictive mediation of television content. These results suggest that the encouragement provided by educators and policymakers for parents to provide parental mediation may not be sufficient to empower parents in their efforts to guide their children's media use. Instead, the necessary empowerment may come from participation in adult media literacy programs (Leivens, 2015) that train parents how to evaluate media sources and content critically, in addition to teaching them about the role of parents in altering children's responses to media exposure (Livingstone et al., 2005). Such media literacy programs, by increasing adults' ability to process media messages logically and critically, may also give adults at least some of the tools necessary to effectively communicate with their children about media and media content. Results of this study suggest that these programs should also include lessons aimed at improving parents' attitudes about parental mediation in order to ultimately motivate parents to engage in parental mediation behaviors.

Results show that the relationship between parents' critical thinking about media and the frequency of their provision of both active and restrictive mediation is mediated by parents' attitudes toward parental mediation. Parents who are better able to think critically about media reported more positive attitudes about participating in media-related parent-child interactions, and these positive attitudes, in turn, are associated with more frequent provision of parental mediation. Thinking critically about media content and sources can help increase one's skepticism toward media messages (Austin, Pinkleton, Hust, \& Cohen, 2005) and such critical thinking and skepticism can result in a desire to protect oneself and one's children from messages that could negatively influence their well-being (Nathanson et al., 2002). In other words, parents with greater ability to think critically about media will likely engage in more frequent parent-child interactions about media use. While the present study is consistent with a substantial body of research establishing such a relationship between attitudes toward behaviors and subsequent behaviors, the current study is unique in that it provides empirical evidence of the relationship between attitudes toward parental mediation and actual parental mediation behaviors. Future research should explore these associations within a framework, such as protection motivation theory, capable of elucidating the cognitive pathways that may mediate the relations found herein.

In order to understand whether or not parents engage in regular parental mediation, some extant parental mediation research has focused on identifying the 
precursors of mediation efforts. Although findings from the current study are correlational in nature, they suggest that parents' critical thinking about media may be an important precursor to the provision of parental mediation. While the study's findings offer opportunities for future media literacy efforts, some limitations merit discussion.

First, the data are correlational in nature, and as such, cannot establish causality. Perhaps parents' engagement in parental mediation activities encourages them to become more critical media consumers. It is possible that these behaviors lead to more positive attitudes about parental mediation in a manner consistent with the way people change their attitudes to make them consistent with their behaviors, as posited by dissonance theory (see, e.g., Harmon-Jones \& Mills, 1999). Although causal ordering of the mediation models in this study cannot be definitively established without longitudinal data, the cited literature alludes to the plausibility of the proposed relations. Future longitudinal or experimental research should investigate these possibilities. In addition, parents' critical thinking about media is only one indicator of the larger construct of media literacy. Future research should explore other aspects of parental media literacy and their relationship with parental mediation. Last, study participants were those who had access to the Internet and were familiar with taking online surveys. It is possible that participants' responses differ from those that might be provided by people less familiar with the Internet or who have limited Internet access. Future research should employ data collection methods that can capture both online and offline populations.

The present study provides an initial answer to the call for the creation of conversations between the fields of media literacy and parental mediation. As far as we know, this is the first study to show a positive association between parents' critical thinking about media and the frequency of their provision of parental mediation. Further, parents' critical thinking about media appears to influence parental mediation behaviors by first influencing attitudes about parental mediation, a pattern that is consistent with decades of research on attitudebehavior relations. Policymakers, educators, and pediatricians should use this knowledge to influence children's responses to media exposure by developing adult media literacy programs that are capable of empowering parents to engage in parental mediation activities.

\section{References}

AAP (2011). Media use by children younger than 2 years: Council of communications and media. Pediatrics, 128, 1040-1045. doi: http://dx.doi.org/10.1542/peds.2011-1753

Ajzen, I. (2012). Martin Fishbein's legacy: The reasoned action approach. The Annals of the American Academy of Political and Social Science, 640, 1127. doi:10.1177/0002716211423363

Aufderheide, P. (1993). Media literacy: A report of the National Leadership Conference on Media Literacy. Washington, DC: Aspen Institute. 
Austin, E. W., Hust, S. J. T., \& Kistler, M. E. (2009). Powerful media tools: Arming parents with strategies to affect children's interactions with commercial interests. In T. J. Socha \& G. H. Stamp (Eds.), Parents and children communicating with society: Managing relationships outside of home (pp. 215-240). New York: Routledge.

Austin, E., C. Knaus, and A. Meneguelli. (1997). Who talks how to their kids about TV: A clarification of demographic correlates of parental mediation patterns. Communication Research Reports, 14, 418-430. doi: 10.1080/08824099709388685

Austin, E. W., \& Pinkleton, B. E. (2001). The role of parental mediation in the political socialization process. Journal of Broadcasting \& Electronic Media, 45, 221-240. doi: 10.1207/s15506878jobem4502 2.

Austin, E. W., Pinkleton, B. E., Hust, S. J. T., \& Cohen, M. (2005). Evaluation of an American legacy foundation/Washington state department of health media literacy pilot study. Health Communication, 18, 75-95. doi: 10.1207/s15327027hc1801_4

Austin, E. W., Pinkleton, B. E., Radanielina-Hita, M. L., \& Ran, W. (2015). The role of parents' critical thinking about media in shaping expectancies, efficacy, and nutrition behaviors for families, Health Communication, 30, 1256-1268. doi:10.1080/10410236.2014.930550

Barber, J. S. (2001). Ideational influences on the transition to parenthood: Attitudes toward childbearing and competing alternatives. Social Psychology Quarterly, 64, 101-127.

Bleakley, A., Vaala, S., Jordan, A. B., \& Romer, D. (2014). The Annenberg media environment survey: Media access and use in U.S. homes with children and adolescents. In A.B. Jordan \& D. Romer (Eds.). Media and the well-being of children and adolescents, pp. 1-19. New York, NY: Oxford University Press.

Brown, A., Shifrin, D. L., \& Hill, D. L. (2015). Beyond 'turn it off': How to advise families on media use. AAP News, 36, Retrieved November 19, 2015 from http://www.aappublications.org/content/36/10/54

Browne, N. (1999). Young children's literacy development and the role of televisual texts. New York, NY: Falmer Press.

Buhrmester, M., Kwang, T., \& Gosling, S. D. (2011). Amazon's Mechanical Turk: A new source of inexpensive, yet high-quality, data? Perspectives on Psychological Science, 1, 3-5.

Buijzen, M., \& Valkenburg, P. (2005). Parental mediation of undesired advertising effects. Journal of Broadcasting \& Electronic Media, 49. 153165. doi:10.1207/s15506878jobem4902_1

Bushman, B. J., \& Cantor, J. (2003). Media ratings for violence and sex: Implications for policymakers and parents. American Psychologist, 58, 130-141 doi:http://dx.doi.org/10.1037/0003-066X.58.2.130

Bybee, C., Robinson, D., \& Turow, J. (1982). Determinants of parental guidance of children's television viewing for a special subgroup: Mass media scholars. Journal of Broadcasting, 26, 697-710.

doi:10.1080/08838158209364038 
Byrne, S. \& Lee, T. (2011). Toward predicting youth resistance to Internet risk prevention strategies, Journal of Broadcasting \& Electronic Media, 55, 90-113. doi:10.1080/08838151.2011.546255

Casler, K., Bickel, L., \& Hackett, E. (2013). Separate but equal? A comparison of participants and data gathered via Amazon's MTurk, social media, and face-to-face behavioral testing. Computers in Human Behavior, 29, 21562160. doi: 10.1016/j.chb.2013.05.009

Center for Media Literacy. (2015). Empowerment through education. Retrieved November 20, 2015 from http:// www.medialit.org/readingroom/empowerment-through-education

Chakroff, J., \& Nathanson, A. I. (2008). Parent and school interventions: Mediation and media literacy. In S. L. Calvert \& B. J. Wilson (Ed.), The handbook of children, media, and development (pp. 552-576). West Sussex, England: Blackwell.

Chan, K., \& McNeal, J. U. (2003). Parental concern about television viewing and children's advertising in China. International Journal of Public Opinion Research, 15, 151-132. doi: 10.1093/ijpor/15.2.151

Dixon, G. N., McKeever, B. W., Holton, A. E., Clarke, C., \& Eosco, G. (2015). The power of a picture: Overcoming scientific misinformation by communicating weight-of-evidence information with visual exemplars. Journal of Communication, 65, 639-659. doi: 10.1111/jcom.12159

Dorr, A., Kovaric, P., \& Doubleday, C. (1989). Parent-child coviewing of television. Journal of Broadcasting \& Electronic Media, 33, 35-51. doi: 10.1080/08838158909364060.

Green, S. B. (1991). How many subjects does it take to do a regression analysis? Multivariate Behavioral Research, 26, 499-510.

Fisher, D. A., Hill, D. L., Grube, J. W., Bersamin, M. M., Walker, S., \& Gruber, E. L. (2009). Televised sexual content and parental mediation: Influences on adolescent sexuality. Media Psychology, 12, 121-147. doi: 10.1080/15213260902849901.

Harmon-Jones, E., \& Mills, J. (Eds.). (1999). Cognitive dissonance: Progress on a pivotal theory in social psychology. Washington, DC: American Psychological Association.

Hayes, A. F. (2013). Introduction to mediation, moderation, and conditional process analysis: A regression-based approach. New York, NY: Guilford Press.

Hindin, T. J., Contento, I. R., \& Gussow, J. D. (2004). A media literacy nutrition education curriculum for Head Start parents about the effects of television advertising on their children's food requests. Journal of the American Dietetic Association, 104, 192-198. doi: 10.1016/j.jada.2003.11.006

Hogan, M. (2001). Parents and other adults: Models and monitors of healthy media habits. In D. G. Singer \& J. L. Singer (Eds.). Handbook of children and the media (pp. 663-680). Thousand Oaks, CA: Sage.

Hutchinson, M. K., \& Wood, E. B. (2007). Reconceptualizing adolescent sexual risk in a parent-based expansion of the theory of planned behavior. 
Journal of Nursing Scholarship, 39, 141-146. doi: 10.1111/j.15475069.2007.00159.x

Jordan, A. B., Hersey, J. C., McDivitt, J. A., \& Heitzler, C. D. (2006). Reducing children's television-viewing time: A qualitative study of parents and their children. Pediatrics, 118, 1303-1310. doi:http://dx.doi.org/10.1542/peds.2006-0732

Kellner, D., \& Share, J. (2005). Toward critical media literacy: Core concepts, debates, organizations, and policy. Discourse: studies in the cultural politics of education, 26, 369-386. doi: 10.1080/01596300500200169

Kraus, S. J. (1995). Attitudes and the prediction of behavior: A meta- analysis of the empirical literature. Personality and Social Psychology Bulletin, 21, 58-75. doi: 10.1177/0146167295211007

LaMarre, H. (2013). When parody and reality collide: Examining the effects of Colbert's super PAC satire on issue knowledge and policy engagement across media formats. International Journal of Communication, 7, 394413.

Leivens, E. (2015). Children, protection of, In R. Mansell \& P. H. Ang (Eds.), The international encyclopedia of digital communication and society, pp. 5358. West Sussex, UK: Wiley-Blackwell.

Livingstone, S., Van Couvering, E. \& Thumim, N. (2005). Adult media literacy: A review of the research literature. London: Ofcom.

Maria, D. S., Markham, C., Bluethmann, S., \& Mullen, P. D. (2015). Parent-based adolescent sexual health interventions and effect on communication outcomes: A systematic review and meta-analyses. Perspectives on Sexual and Reproductive Health, 47, 37-50. doi: 10.1363/47e2415

McEachan, R. R. C., Conner, M., Taylor, N. J., \& Lawton, R. J. (2011). Prospective prediction of health-related behaviours with the Theory of Planned Behavior: A meta-analysis. Health Psychology Review, 5, 97-144. doi:10.1080/17437199.2010.521684

Meirick, P. C., Sims, J. D., Gilchrist, E. S., Croucher, S. M. (2009). Parents' perceptions of education and materialism as media effects on their own and other children. Mass Communication and Society, 12, 217-237. doi: $10.1080 / 15205430802439554$

Mendoza, K. (2009). Surveying parental mediation: Connections, challenges and questions for media literacy. Journal of Media Literacy Education, 1, 2841.

Nathanson, A. I. (2001). Mediation of children's television viewing: Working toward conceptual clarity and common understanding. In W.B. Gudykunst (Ed.), Communication Yearbook, 25 (pp. 115-151). Mahwah, NJ: Lawrence Erlbaum.

Nathanson, A. I., Eveland, W. P., Park, H. S., \& Paul, B. (2002). Perceived media influence and efficacy as predictors of caregivers' protective behaviors. Journal of Broadcasting and Electronic Media, 46, 385-411. doi: 10.1207/s15506878jobem4603 5

O'Keefe, D. J. (2002). Persuasion: Theory \& research (2nd ed.). Thousand Oaks, CA: Sage. 
Ofcom (2014). Children and parents: Media use and attitudes report. Retrieved November 20, 2015 from

http://stakeholders.ofcom.org.uk/binaries/research/media-literacy/mediause-attitudes-14/Childrens_2014_Report.pdf

Pequegnat, W. \& Szapocznik, J. (2000). The role of families in preventing and adapting to HIV/AIDS: Issues and answers. In W. Pequegnat \& J. Szapocznik (Eds.), Working with families in the era of HIV/AIDS, (pp. 326). Thousand Oaks, CA: Sage.

Pew. (2005). New concerns about Internet and reality shows: Support for tougher indecency measures, but worries about government intrusiveness. Retrieved November 19, 2015 from http://www.peoplepress.org/files/legacy-pdf/241.pdf

Potter, W. J. (2010). The state of media literacy. Journal of Broadcasting \& Electronic Media 54, 675-696. doi: 10.1080/08838151.2011.521462

Potter, W. J. (2014). Media literacy ( $7^{\text {th }}$ ed.). Thousand Oaks, CA: Sage.

Rasmussen, E. E. (2013). Theoretical underpinnings of reducing the media's negative effect on children: Person-centered, negative-evaluative mediation within a persuasion framework. In E.L. Cohen (Ed.). Communication Yearbook 37, (pp. 379-406). New York: Routledge.

Rich, M. (2014). Moving from child advocacy to evidence-based care for digital natives. JAMA Pediatrics, 168, 404-406. doi: 10.1001/jamapediatrics.2014.55

Rich, M., \& Bar-on, M. (2001). Child health in the information age: Media education of pediatricians. Pediatrics, 107, 156-162. doi:http://dx.doi.org/10.1542/peds.107.1.156

Rideout, V. J., Foehr, U. G., \& Roberts, D. F. (2010). Generation M2: Media in the lives of 8-to 18-year-olds (Publication \#8010). Menlo Park, CA: Kaiser Family Foundation. Retrieved November 19, 2015 from http://files.eric.ed.gov/fulltext/ED527859.pdf

Smith, E. R., \& Mackie, D. M. (2007). Social psychology ( $3^{\text {rd }}$ ed). New York, NY: Psychology Press.

Strasburger, V. C., Wilson, B. J., \& Jordan, A. B. (2014). Children, adolescents, and the media (3rd ed.). Thousand Oaks, CA: Sage Publications.

Tsfati , Y. , Ribak , R. , \& Cohen , J. (2005). Rebelde Way in Israel: Parental perceptions of television and monitoring of children's social and media activities . Mass Communication \& Society, 8, 3-22. doi: 10.1207/s15327825mcs0801_2

U.S. Census Bureau (2015). Current population survey: Income and earnings summary measures by selected characteristics, 2013 and 2014. Retrieved September 8, 2016 from https://www2.census.gov/programssurveys/demo/tables/p60/252/table1.pdf

Valkenburg, P. M. Krcmar, M., Peeters, A. L., \& Marseille, N. M. (1999). Developing a scale to assess three styles of television mediation: "Instructive mediation," "restrictive mediation," and "social coviewing." Journal of Broadcasting \& Electronic Media, 43, 52-66. doi: 10.1080/08838159909364474 
Valkenburg, P. M., Piotrowski, J. T., Hermanns, J., \& de Leeuw, R. (2013). Developing and validating the perceived parental media mediation scale: A self-determination perspective. Human Communication Research, 39, 445-469.

Vittrup, B. (2009). What US parents don't know about their children's television use: Discrepancies between parents' and children's reports. Journal of Children and Media, 3, 51-67. doi: 10.1080/17482790802576972

Walsh, A., Edwards, H., \& Fraser, J. (2009). Attitudes and subjective norms: Determinants of parents' intentions to reduce childhood fever with medications. Health Education Research, 24, 531-545. doi: 10.1093/her/cyn055

Warren, R. (2001). In words and deeds: Parental involvement and mediation of children's television viewing. Journal of Family Communication, 1, 211231. doi: 10.1207/S15327698JFC0104_0 